\title{
From top-down land use planning intelligence to bottom-up stakeholder engagement for smart cities - a case study: DECUMANUS service products
}

David Ludlow" , Zaheer Khan', Kamran Soomro', Mattia Marconcini', Roberto San Josée, Philippe Malcorps', Maria Lemper', Juan Luis Perez', Annekatrin Metz

\{David.Ludlow, Zaheer2.Khan, Kamran.Soomro\}@uwe.ac.uk

University of the West of England (UWE), Bristol, UK

\{Mattia.Marconcini, Annekatrin.Metz\}@dlr.de

¿German Aerospace Center (DLR), Wessling, Germany

\{Roberto, Jlperez\}@fi.upm.es

${ }^{3}$ Technical University of Madrid (UPM), Madrid, Spain

Philippe.Malcorps@eurosense.com

`EUROSENSE, Wemmel, Belgium

Lemper@geoville.com

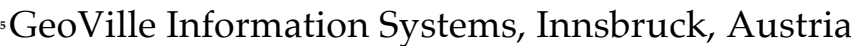

Corresponding author * 


\section{Abstract}

Intelligence delivered by Earth Observation (EO) satellites performs a vital role in supporting ICT enabled urban governance and the development of decision making tools delivering integrated urban planning. This paper reviews the DECUMANUS project experience, detailing the development of the EO derived tools, and providing evaluation of the service products developed to facilitate the deployment of top-down expertise in land use planning decision making. The central purpose of the paper is to assess the potential for use of these DECUMANUS high resolution EO images and data, developed primarily to support top-down expert led integrated urban planning, also to drive applications supporting bottom-up participatory planning, promoting co-design and innovation in a smart city governance process. Based on the DECUMANUS experience, and wider experience derived from a number of EU Smart City governance innovation projects, it is concluded that: i) EO derived images and associated data offer great opportunity to deliver top-down decision making tools, which in combination with additional auxiliary in situ data, including participatory sensing data, effectively support integrated urban planning and ii) EO derived images also offer substantial potential as communication tools essential to the decision making process, enabling citizens to make more informed and responsible choices and participate in co-designed and innovative urban planning.

Keywords: Earth Observation data, top-down integrated urban governance, bottom-up stakeholder participation, co-creation and innovation.

\section{Introduction - Integrated and Participatory Urban Governance}

Certain complexities arise from urban territorial governance that reflect the interconnected social, economic and environmental challenges. These complexities have supported a drive for integration and coordination of effort of the multiple agencies with specific sectoral responsibilities (social, economic and environmental). Another consequence of these complexities is the drive for integration initiatives by planning agencies representing different levels of governance from local to EU. Effective integrated urban governance, even though the effort continues, has proved to be a major challenge, and indeed a challenge too great for expert resolution alone. Accordingly, top-down expertise operating in integration frameworks of cross-sectoral planning teams have increasingly sought the assistance of all stakeholders in a coalition of open governance that strives to respond effectively to the societal challenges of our time.

Out of these challenges has arisen the agenda of open governance and co-production of urban solutions (European Commission, 2013a). The question for urban governance is thereby extended from concerns to create a more integrated management of the territory, which has dominated the transformation agenda for a generation. The new emphasis is now on the means by which more participatory engagement can be achieved. In this new landscape of integrated and participatory urban governance opportunities to harness innovative social and technology solutions, derived directly from bottom-up engagement in the community, are driving expectations of a more effective policy implementation 
supported by the new legitimacy of the stakeholder coalition and the political capital of the community (Misuraca G et al. 2010).

The interplay of social and technological innovation has the potential to transform the governance of our cities, as citizens are demanding more active engagement in the planning of their communities and the visioning of the future city. The old order of expert master planning now shares centre stage with a bottom-up community and neighbourhood planning supported by "mass localism" as a means to help small communities solve big social challenges (Insigt project 2013, Bunt L and Harris M, 2010). At the same time technological innovation is providing new means of community engagement facilitating participation in planning as well as creating the potentials for the definition and delivery of more integrated solutions. The dynamic of social and technological innovation is defining a new smart city governance, addressing the complex challenges of urban planning and governance and simultaneously disrupting the governance model in fundamental ways (European Commission, 2013b).

The central questions for this paper, given the growing dynamic of open and participatory governance, first to what extent do potentials exist for tools designed essentially to support "top-down" expert planning also to serve "bottom-up" plan co-production. The second question asks what is the nature of development that is required to secure these potentials? The decision-making tools described and assessed here in relation to these questions, have been developed in the framework of the EU funded DECUMANUS project (DECUMANUS, 2013).

The structure of this paper is as follows: Section 2 provides an overview of the state of the art in respect of the challenges confronting urban governance, and the nature of responses developed in framework of integrated and participatory governance. Section 2 introduces DECUMANUS service products. Section 4 analyses these services in a systematic analysis approach comparing and contrasting DECUMANUS service products from a variety of perspectives including added value in relation to the current state-of-the-art, extent of stakeholder engagement in their development, development potential in the context of coproduction, as well as stakeholder evaluation of their utility. Section 5 discusses the potentials for citizen engagement in developing "top-down" service products, as well as opportunities for "bottom-up" co-production for enhanced urban governance. Finally, section 6 draws conclusions and future research direction.

\section{Related Work}

Traditionally, satellite-based remote sensing applications, that typify the DECUMANUS products contribute to "top-down" planning applications supporting improved governance and planning. This paper presents the ways in which such services can be used to gain new and frequent land-use information, and also to support city administration to communicate evidence based information with citizens supporting behavioural change and co-creation of new applications in an urban environment. Urban governance (Jacquier, 2008) is identified as a myriad of complex processes, structures and interaction between local government and citizens. Specifically, Eckhardt and Elander (2011) compile in detail issues surrounding 
urban governance and consider it as a shift from traditional, more centralized and hierarchical government. The shift is towards more network and partnership-based structures with the participation of different stakeholders, representing also the market and civil society. It is the shift from traditional hierarchical and expert driven governance to more participatory forms that defines the emergence of "bottom-up" stakeholder engagement as an important principle of urban planning.

A further characteristic of city planning is the complexity and interconnectedness of issues arising in the urban arena, and the need for integrated solutions to support their management, according to principles of sustainable development. The goals of city planning are by their nature broad, varied and complex, its delivery is heavily reliant upon the action of a plurality of actors across different operationally independent policy sectors (Wong, 2011). The process of the development of urban settlements and communities requires comprehensive research and analysis, strategic thinking, knowledge of architecture and urban design, public consultation, policy recommendations, implementation and management (Taylor, 2007).

It is true that these traditional planning methods are simultaneously challenged and enabled by the application of innovative ICT tools and techniques characteristic of smart city governance (Silva, 2010; Yigitcanlar et al, 2008; Kingston, 2007). However, the availability of these ICT tools (e.g. GIS, Web 2.0/3.0) and vast data resources (e.g. Open data initiatives) is also permitting planners greater flexibility to perform planning activities and involve different stakeholders, including citizens (Poplin, 2011; Hanzl, 2007), in informed and participatory decision making processes. Other researchers provide a comprehensive overview and guide for sustainable urban development challenges, for which ICT plays a crucial role for smart and connected cities (United Nations, 2010).

In contrast to "top-down" approaches, "bottom-up" initiatives facilitate public participation in co-producing city plans with emphasis on stakeholder engagement and public participation (Davies et al, 2012; Poplin, 2011; Hanzl, 2007). Examples include visualisation and simulation tools (Khan et al, 2014), mobile phone 3D augmented reality application for Vienna (Lang and Sittler, 2012), SoftGIS for Helsinki (Kahila and Kyttä, 2010; Kyttä, 2011), etc. Generally, innovative ICT tools supporting public participation can be considered as significant drivers of enhanced urban governance where nonetheless the definition of participatory governance remain fluid.

Wampler, and McNulty, (2011) consider participatory governance, '...consists of statesanctioned institutional processes that allow citizens to exercise voice and vote, which then results in the implementation of public policies that produce some sort of changes in citizens' lives...'. Other researchers argue that public participation should be seen as multi-way interaction in which citizens and other stakeholders are involved formally and informally to influence actions in the public arena before it is considered as final conclusion to develop and implement specific policies (Innes and Booher 2004). In addition, Rowe and Fewer (2005) define key concepts in the domains: public communication, public consultation and public participation, to mitigate misconceptions about public participation. They also provide a comprehensive typology of communication, consultation and engagement mechanisms. 
Previously Rowe and Fewer (2000) reviewed different public participation methods and proposed an evaluation framework based on acceptance and process criteria.

The emerging agenda of plan co-production (European Commission, 2013a) is strongly defined by principles of open governance, in which open data linked to open process defines open service, characterised by transparency of process, wide stakeholder engagement, innovative solutions, and more effective democratic outcomes. Stakeholders in this context are involved at the inception of the plan to define the key issues of neighbourhood concern, as well as at various stages in the subsequent development of the plan. This engagement takes place in the framework of simultaneous "top-down" and "bottom-up" development of the plan, and associated decision-making, characteristic of an integrated and participatory urban governance.

Clearly this territory of transformational governance is challenging for all necessary attempts to define a new architecture of smart city enabled integrated and participatory governance and co-production. Innovative ICT tools and services can facilitate this emergence of a integrated and participatory governance characterised by "top-down" and "bottom-up" engagement and co-production in decision-making. In this frame remote sensing, based on earth observation satellite derived data, aim to support planning authorities in securing the intelligence required for evidence based governance decisions.

\section{DECUMANUS - Smart City Governance}

The decision-making tools described and assessed in this paper have been developed in the framework of the EU funded DECUMANUS project (DECUMANUS, 2013). DECUMANUS aims to deliver smart city governance, defined as ICT enabled applications to address urban planning requirements for information and intelligence, assessment and communication in support of integrated decision-making on the spatial development of the city. The principal focus for DECUMANUS service development is the provision of support for "top-down" governance, and assistance for the planning expert in decision-making on specific proposals for development, as well as plan making activity at all scales from neighbourhood, to citywide and city-region levels.

The DECUMANUS project is one example where remote sensing data is used to deliver various services supporting climate modelling, citizen health, energy efficiency, land monitoring and population impact assessment. Stakeholder engagement in service delivery, including that of citizens, is primarily limited to formal consultation periods, with planning experts leading all aspects of decision-making and plan development. DECUMANUS service products are therefore not specifically designed to support the "bottom-up" participatory processes, and engagement of stakeholders that extends beyond formal consultation in the plan approval process to various forms of co-production of the plan. These DECUMANUS service products are demonstrably useful for strategic and "top-down" planning, but deeper consideration is needed to assess the relevance and usefulness of these products for cocreation and co-production of plans supported by smart city participatory applications.

The DECUMANUS project aims to design and develop a set of geo-spatial products and services supporting urban planning. The project team includes five city partners, Antwerp, 
Helsinki, Royal Borough of Kensington and Chelsea (London), Milan and Madrid, participating to assist in defining city requirements and validate the service products. The key objective of the project is to provide city managers with enhanced land use planning decision support services, based on the deployment of geo-spatial products, that address the diverse challenges of sustainable urban development.

The project utlises Copernicus (Copernicus, 2016) data, drawing on experience from previous EU and European Space Agency (ESA) projects (e.g. BRIDGE, GUS, Geoland) in the development of city specific service products. The objective is to generate reliable, accurate and high resolution (i.e. urban scale) information and intelligence to assist urban planners and decision-makers in making decisions for land-use changes, environmental changes and climate change adaptation. This requires the adaptation of Copernicus products to urban scales and development of innovative tools and services to meet the specific needs and requirements of cities and diverse stakeholders. Accordingly, DECUMANUS product development and assessment is necessarily and fundamentally expert user driven.

The DECUMANUS portfolio of services assist in the monitoring and assessment of land-use development in responding to the key political concerns for Europe's cities including climate change, urban sprawl, energy efficiency and securing healthy urban environments for all citizens including the vulnerable young and increasingly ageing population of Europe. The portfolio is specified in terms of tools focussed on land monitoring, city energy efficiency, citizen health and population impact assessment, and divided into two essential scales of assessment:

- Strategic Services including products that support the management and implementation of climate and environmental change adaptation strategies at a citywide and / or city-regional scale.

- Local Services including datasets, indicators, models, etc. that provide information at much higher resolutions than the strategic services with a view to support local-level decision-making, and developed and specified according to substantial stakeholder engagement.

The following Figure 1 illustrates interaction of end users (city stakeholders e.g. urban planners, GIS experts etc) with the DECUMANUS services via a web based geo-portal. End users are expected to perform certain pre-defined operations (as per requirements definition (DECUMANUS, 2014) and receive corresponding responses (e.g. data, image, result visualisation etc) via the geo-portal. For instance, one common requirement is that the output of DECUMANUS services should be linkable as a layer on local city Atlas and can be used for further analysis, consultation, awareness raising, etc.

All service features are covered in the background processing which actually fulfils user requirements. End users can only perform pre-defined interactive operations e.g. data export. The outcome of the service can also be linked with city atlas through service interfaces (e.g. OGC compliant services) and used for further processing. However, DECUMANUS can provide outputs in commonly used formats (e.g. shapefiles, vector/raster data, tables, JSON etc) and further transformation of data is beyond the scope of DECUMANUS services. 
The project adopted the CoReS method (Khan, Ludlow, and Loibl, 2013) for collecting city requirements for the development of above services. In this respect, requirements questionnaire were sent to all five city stakeholders for preparing groundwork and context followed by requirements workshop where city stakeholders mainly domain experts i.e. climate experts, public health experts, urban planners, transport planners, air quality experts, environmentalists and GIS experts participated in defining the needs and requirements.

In DECUMANUS two types of evaluation were performed; user and technical. In user evaluation the domain expert users were consulted about the benefits, relevance, usability and functionality of the service products. Technical evaluation focused on the technical quality of the products in terms of performance and functionality. Evaluation of the DECUMANUS services was undertaken according to the following methodology:

1) Evaluation Design: at the evaluation design stage, the Criteria-Indicators-Metrics (CIM) Methodology (Khan, Ludlow and Caceres 2013) was extended by the authors to form CIM2, based on the more recent ISO 25010 Quality in Use model, as compared with CIM the ISO 9126 Quality Model (Chua and Dyson 2004; Lew et al. 2010). The methodology is based on defining set criteria and indicators to measure the usefulness of applications by answering specific questions. Criteria include usability, functionality, performance, user acceptance, effectiveness, efficiency, compatibility and reliability. In addition to quantitative measures, qualitative assessment is also included, to enable evaluators to provide subjective (and/or objective) assessments mainly concerning the benefits, relevance and the overall expected impact of the DECUMANUS solutions. More specifically, the following activities were performed by the authors:

a. Identification of the main set of criteria based on the requirements specification, application objectives and stakeholder needs;

b. Deriving sub-criteria for each criterion and operationalizing it by identifying one or more indicators to achieve the objectives of the project and its applications;

c. Specifying questionnaire and response options with associated weights to measure the outcomes. Each indicator is represented by one or more questions;

d. Identifying the means to perform specific evaluation exercises to answer the evaluation questions.

2) Design Verification: the evaluation design was verified by engaging with stakeholders in each city who were asked to perform the following activities:

a. Verify that the evaluation design contents (i.e. criteria, questionnaire, etc) captured important assessment elements and were in line with their needs and requirements;

b. Highlight the importance (high, medium, low) of specific questions;

c. Indicate improvements in the questionnaire, response options, metrics etc and

d. Identify additional criteria, indicators, questionnaire and metrics, where applicable. 
3) Technical Evaluation: In this phase developers performed technical evaluation of their respective products including unit tests, performance and functionality testing. The objective here was that the service products are error free before delivering to city stakeholders.

4) Evaluation Implementation: in this stage the user evaluation was carried out by using different mechanisms such as web-based tools, workshops, etc.

5) Evaluation Results and Documentation: all the above stages including evaluation results were documented and verified by the city stakeholders.

\section{DECUMANUS Services - Systematic Analysis Approach}

In order to understand DECUMANUS service products and identify their potential to support co-production a systematic analysis approach is adopted. This approach addresses both qualitative and quantitative aspects as a basis for discussion and assessment of DECUMANUS service products, as presented in

Table 1. The five elements: product description, added value, stakeholder engagement, product development and user evaluation cover various aspects of DECUMANUS service products including potential for co-creation. The objective here is to introduce these DECUMANUS service products using a consistent approach which can provide necessary information for analysis and discussion.

\subsection{Green Roof and Tree Mapping using Land Monitoring Service}

Product Description: The strategic implementation of green infrastructures can effectively mitigate the adverse effects of climate change in urban areas by reducing high temperatures, decreasing storm water runoff, and simultaneously save energy, improve air quality and increase biodiversity. In this framework, DLR (German Aerospace Agency) developed two services concerning green roofs and urban trees.

Green roofs are gaining increasing attention as a versatile new environmental mitigation technology. Advantages include absorbing rainwater, providing thermal insulation, increasing energy efficiency, as well as reducing air pollution and electromagnetic radiation. Mapping green roofs is clearly essential to their promotion, and the DECUMANUS current and potential green roof mapping service permits automatic identification of green roofs, as well as determination of which roofs can be potentially converted into green roofs together with expected impacts. The mapping methodology analyses slope from LiDAR height data to identify flat roofs. Subsequently green roofs are identified as exhibiting consistent vegetation coverage according to a normalized difference vegetation index (NDVI) computed from airborne/satellite colour-infrared (CIR) imagery. All remaining flat roofs are denoted as potential green roofs, and their impact is estimated according to the local surface imperviousness, where the higher the imperviousness in the surroundings, the higher the expected impact. Figure 2 depicts green roof potential for Helsinki study area.

Urban trees also perform invaluable environmental mitigation services absorbing carbon dioxide while releasing oxygen back into the air, cooling the cities by shading, reducing runoff by breaking rainfall, as well as providing habitat for wildlife. The DECUMANUS tree 
location and canopy mapping service permits full benefit to be taken from these services, delivering a precise knowledge of the tree distribution and their canopy within urban areas. The mapping methodology first identifies all vegetated areas by the analysis of the NDVI calculated from the CIR data; then the tree canopy is delineated accounting for LiDAR height information, and finally tree location is defined according to the highest peak of the crown, as depicted in Figure 3.

Concerning the current and potential green roof mapping service, it is worth noting that the main idea of the implemented method is to avoid missing the detection of any building hosting a green roof. Accordingly, parameters are set in order to obtain a low amount of false alarms to be refined in the post-processing visual check. In this framework, final output products are expected to be correct with, in case, negligible misclassification (indeed, any identified error is properly corrected in the post processing).

As regards the tree canopy and location mapping service, a comprehensive assessment of the generated products has been carried out based on validation information derived from extensive photointerpretation. Specifically, for each city 3000 pixels corresponding to canopies and 3000 pixels from all the remaining areas have been defined and compared to the corresponding labels automatically associated by the implemented method. Similarly, the location of 3000 trees has also been manually defined and checked (with a tolerance of $2 \mathrm{~m}$ ) against the locations estimated by the developed technique. In both cases, overall accuracies higher than $95 \%$ have been obtained.

Added Value: Mapping and monitoring green roofs and urban trees is of great value for urban planners in the effective design of climate change adaptation and mitigation strategies. To date this activity has been supported by in situ surveys or photointerpretation of very high resolution airborne imagery, both very costly in terms of time and money. In contrast, the green roof and tree mapping services are almost fully automatic, with only visual check of the results required at the end of the processing chain, representing major saving of cost and production time, and simple update. For green roofs, update is critical as reliable knowledge of their location is essential to check whether the green roof is correctly maintained. Beyond this the potential green roof and impact mapping represents a unique service developed by DECUMANUS.

For tree monitoring, in many cities there are typically incomplete or non-existent inventories, often compiled by volunteers lacking suitable quality control practice. In this context, the advantages of the service are clear, as they deliver a standardized procedure which can be effectively applied to cities of any size. Furthermore, the resulting tree register permits identification of new planting areas and supports education of the public and decision makers about their importance.

Stakeholder Engagement: The current and potential green roof mapping service has been developed in response to the requirements from the DECUMANUS partner cities of Antwerp, Helsinki, Milan and the Royal Borough of Kensington and Chelsea, London (RBKC). Specifically, in these four municipalities intensive consultations took place with urban planners and policy makers in identifying effective regulations to promote the installation of new green roofs. These discussions furthermore identified the need to estimate 
which roofs can potentially be converted into green roofs, as well as giving an indication of where this conversion might be overall most beneficial.

The tree location and canopy mapping service was developed in response to specific requests from Helsinki and RBKC to support their urban green policies. In particular, for Helsinki the most pressing requirement was to reliably map the tree canopy surface within the entire greater metropolitan area, more than $700 \mathrm{~km}^{2}$, and from RBKC in response to request from the Greater London Authority to identify the location of all the existing trees within the Borough. In both cases, the partner cities were interested in maps automatically generated from EO imagery, avoiding the long and costly manual processing. Accordingly, the cities provided the necessary input data (digital surface and terrain models, airborne CIR imagery, building outlines, etc.) and offered constructive feedback on the service development process, ensuring the final products met the original expectations.

Product Development: Direct engagement of citizens could further improve the development of the mapping services, in two respects. First, in assessing the effectiveness of the final products by performing in situ validation in their neighbourhood or workplace. For example, for green roofs service citizens can easily assess the reliability of the different products, by verifying the information for the roofs of buildings where they live or work. On the other hand, citizens might add further value to the products by including supplementary key information, for example, in the case of trees in detailing their species. This species aspect is of particular interest as knowledge of the exact type of trees is not an easy task even using EO data. Very high resolution hyperspectral imagery can identify species, but it is only available via airborne missions with extremely high costs. In both cases, the most effective means of engaging citizens is the development of dedicated mobile apps which can be easily installed on smartphones provided with GPS. In particular, they should be fast to launch, automatically linked to the most updated version of the different products, and permit the submission of feedback within a few clicks.

Stakeholder Evaluation: From Milan one expert user representing the municipality participated in the evaluation of the premium land monitoring service, emphasising the following aspects of the service:

1) helps to monitor the increase in green roofs over time.

2) helps to perform detailed analysis of land use, both present and future in order to assess the effects of PGT (i.e. Land Management Plan of Milano 2012) enforcements on environmental monitoring.

3) supports evidence-based planning and decision-making and improvements in PGT.

From Helsinki two expert users participated and appreciated the novel information provided for the region, that the outputs can be integrated with Helsinki's Regional Environmental Atlas, and the intuitive and easy-to-use user interface.

\subsection{Climate Atlas and Health Impact Services}

Product Description: These services connect global climate change to urban meteorological conditions, air pollution concentrations and epidemiological endpoints. The final products, developed by UPM, indicate how urban meteorological conditions and air pollution 
concentrations respond to different climatic conditions and emission scenarios and how human health could be affected by changes induced by global climate change using different IPCC (Intergovernmental Panel on Climate Change) ${ }^{1}$ climate scenarios, e.g. RCP4.5 climate scenario as depicted in Figure 4.

The services focus on the direct effects of global climate with very high spatial resolution which permits assessment of the geographical variability of impacts over the cities, and so help to identify city areas with higher exposure to the global climate change. For example Figure 5 shows a Madrid area with higher exposure to global climate for the climate scenario RCP 8.5 as compared with scenario RCP 4.5, based on an exposure intensity indicator which combine 15 climate indicators.

The simulation periods are 2011 (base), 2030, 2050, 2100 based on IPCC AR5 (Fifth Assessment Report) global climate scenarios: RCP4.5 and RCP8.5. RCP4.5 assumes stabilization after 2100 by employment of a range of technologies and strategies for reducing greenhouse gas emissions. RCP8.5 pathway arises from little effort to reduce emissions and represents a failure to curb warming by 2100 .

During the first phase of the project Strategic products were developed for the cities of Madrid, Milan, Helsinki, Antwerp and London with 200 meter of spatial resolution using a mixed (dynamical/diagnostic) dynamical downscaling approach to proceed from global data to urban data. For premium services, second phase of the project, a full dynamical downscaling process was implemented, from $1^{\circ}$ spatial resolution (global climate models) up to 50 meters spatial resolution, using a computation fluid dynamical model, for Madrid, Milan and London.

Added Value: The urban climate and health impact services are developed to assist planning authorities to identify the different sensitivities of various areas of the city to global climate change. Urban planners can use the products and intelligence created during the initial phases of urban planning to identify the most vulnerable areas of the city, the urgency of the adaptation actions and to explore potential adaptation strategies and resilience measures.

A prime added value of these services is the very high spatial horizontal resolution (up to 50 meters), which permits visualisation of urban climatic conditions in relation to the complex building morphologies of cities. Furthermore, as an integrated global climate impact assessment tool it takes account of climate, air pollution and health impacts at the same time. The very high spatial horizontal resolution combined with the integrated perspective permit understanding of the local urban climate, air pollution conditions and health impacts, (as depicted in Figure 6) and hence identify appropriate planning measures to mitigate adverse effects.

Stakeholder Engagement: The Urban Climate Atlas and Citizen Health services have been developed in active consultation with Madrid, Milan and London stakeholders to design and implement the services. During the first phase of the project (Strategic products), stakeholders participated in the design of the services:

IPCC URL: http:/ / www.ipcc.ch / 
- Selecting the simulation years: 2030, 2050 and 2100

- Selecting the city study areas

- Advising on selection of different indicators

- Supplying the input data

Design of the local products was more collaborative, notably in the case of Milan, where design of the product was driven by the city domain experts, with technical advice from the service provider. This collaboration enabled a series of additional products to be developed that met the specific needs of Milan, particularly emission reduction strategies to improve air quality and the health of citizens. Milan planners aim to use the products to develop Action Plans to reduce the air pollution impacts and associated health impacts. Overall, this collaborative approach demonstrates a strong bottom-up methodology, while for the strategic product a more top-down paradigm was pursued.

Product Development: Direct engagement of citizens could further improve the development of the Urban Climate Atlas and Citizen Health services as capacity building in the community is one of the main action lines in the implementation of adaptation strategies to reduce climate impacts, and minimize adverse consequences to citizens. It is difficult for citizens to see climate change impact on their local neighbourhood and in this respect this service acts as an effective communication and raise awareness. In this respect full stakeholder collaboration, including citizen engagement is essential to the design and specification of adaptation and mitigation strategies including behavioural change. This is especially the case, as here, where expensive and long-term projects are required in the design and implementation phases of the tools.

Stakeholder Evaluation: Design and implementation of the Urban Climate Atlas and Citizen Health services was achieved on the basis of substantial engagement with Madrid, Milan and London stakeholders, although Milan provided the most well developed collaborative experience. In Milan the Energy, Environmental and Mobility Planners of the City together with technicians and researcher of AMAT (Municipal Agency for Mobility, Environment and Territory) particularly recognised the benefits of the city level detail of climate change impacts in respect of air quality and related health effects, in permitting evaluation of alternative local action scenarios proposed in relation to energy and mobility. Such evaluation also permits translation of environmental effects into external costs, providing an innovative decision support tool defining future strategic environmental assessments.

\subsection{Energy Efficiency Service}

Product Description: Efficiency is an increasing city concern driving the demand for specific products that indicate energy losses and potential savings. EUROSENSE developed the Energy Efficiency service with focus on the contributions of cities to increasing atmospheric concentrations of greenhouse gases due to the inefficient use of energy. The service detects areas that are least energy efficient and assesses the potential for the installation of solar panels. EO-based information products have been developed in three respects: thermal energy loss due to building heating, excessive lighting (night-time lights), and roof photovoltaic potential. As an example, Figure 7 depicts determination of roof photovoltaic 
potential for the city of Antwerp using different approaches. Similarly, Figure 8 depicts night time light emission for Madrid and identify areas of excess light/energy loss.

The broad resolution of the Strategic Service makes it useful for analyses at neighbourhood scale (several building blocks) and inter-city comparisons, and given the repetitive coverage of satellite data, it can also be used as evidence-based policy support for retrofitting campaigns. On the other hand, the high-resolution Local Service provides enough detail to detect and moreover to identify energy losses at building and street light scales. It also enables evaluation of the photovoltaic potential of each building roof by determining areas suitable areas for the installation of solar panels and the corresponding expected electricity yield. These differences between the Strategic and the Local Services also make their use complementary. The former aimed mainly at city authorities who can use it as a decisionsupport tool for large-scale programs, while the Local Service can also be used by the citizens to assess the energy efficiency of their property.

Added Value: The Strategic service, enables city planners to locate neighbourhoods with anomalously high energy losses from building roofs, and also to detect city light spots at a neighbourhood scale, and to monitor light emissions over time (See Figure 8). Accordingly, the service can be used as evidence-based policy support for citizen awareness raising and large-scale retrofitting campaigns across the city. The Local Service can assist city planners to launch campaigns targeting citizens to improve roof insulation and the installation of solar panels. Each citizen is able to verify the quality of their roof insulation on a map, as well as the areas suitable for the installation of solar panels and the corresponding potential electricity yield. Moreover, the city planners can use this service to make an overall evaluation of the street lighting network at a very detailed scale. The luminance values are compared to European standards to detect over-exposed areas and thus potential areas for energy saving.

Stakeholder Engagement: The Energy Efficiency service was developed in response to the requirements of Antwerp, Helsinki, Madrid, Milan and RBKC. The first and main objective expressed by the cities regarding energy targets the reduction of greenhouse gas emissions. For instance, Antwerp, Helsinki, Madrid and Milan have all signed the Covenant of Mayors Accord, thereby committing them to reduce at least $20 \%$ of their $\mathrm{CO}_{2}$ emissions by 2020. In order to meet these commitments, the cities highlight two major components of city energy consumption, and hence of potential energy savings, building heating and night-time lighting. In this respect the cities have all the data they need, but lack a spatially explicit translation of the data. The Energy Efficiency service meets this latter requirement in detecting and identifying energy loss at the neighbourhood scale (Strategic Service) and at the building and street light scale (Local Service). At the same time it enables assessment of the potential electricity yield resulting from the installation of photovoltaic panels and, derived from that, the corresponding reduction of $\mathrm{CO}_{2}$ emissions.

The second main demand from the cities is to raise awareness among citizens as private building heating constitutes the largest part of heat loss at city scale, and without the active participation of the individual citizen, no large-scale improvements can be expected in energy efficiency. This objective requires an easy and intuitive way of presenting the data to the public, thereby potentially triggering incentives for personal intervention. The Local 
Service, offers an easy-to-handle interpretation key, so any citizen is able to verify the quality of its roof insulation, based on high resolution data $(50 \mathrm{~cm})$ which allows detailed diagnosis. The citizen can also check the suitability of their roof for the installation of solar panels, by looking at the expected annual electricity yields.

Product Development: For the production of the thermographic map, the participation of the citizens is essential at development stage. By giving information about their roof insulation material and by measuring temperatures under their roof during the night of the thermographic survey flight, they permit effective thermal calibration of the data. The heat losses measured by the flight are homogenised among the whole area and are converted in terms of roof insulation quality. However, the number of citizens who participate in this process is often too small and product quality would beneficiate from the involvement of more citizens. Effective publicity campaigns raising environmental awareness should support greater public engagement. Furthermore, some Energy Efficiency Service products are directly aimed at citizens, and using the Local Service, any citizen can check the quality of their roof insulation and the potential for the installation of solar panels. It is therefore important to develop meaningful and easy to handle web platforms or mobile phone applications in order to make this information accessible to the citizens. Interactivity could be also improved, permitting citizens to comment on the reliability of the results and add information. For example, for the Photovoltaic Potential Service, citizens with solar panels could compare their actual electricity yield with the estimations, feedback that would improve the service. Finally, by developing such tools, the deployment of the Energy Efficiency Service represents a great opportunity for city authorities to create dialogue with their citizens on environmental issues and promote their eco-friendly actions.

Stakeholder Evaluation: For the Energy Efficiency Service seven users from RBKC participated in the evaluation process. The evaluators found the service intuitive and useful in helping to identify light spots as well as potential suitable locations for solar panels. Moreover, the ability to show potential energy savings from solar panel installations was also viewed as a positive feature. The service was seen as of benefit for engaging with residents and for supporting energy saving initiatives, and it was considered that the service could have a significant role in decision-making and planning processes. However, some users also found the service difficult to understand, and it was suggested that adding improved legends and explanations for the maps would increase the effectiveness of the tool.

\subsection{Population Impact Assessment Service}

Product Description: Climate change is impacting the earth, with predicted more frequent heat waves and extreme colds, floods, storms and droughts. In this context, it is ever more vital for urban citizens, city authorities, national and EU institutions to understand how they will be affected and to plan accordingly. This requires exact measurements on the location of the population and how they are exposed to these threats. Today, most European cities have information on the population distribution and density available, mostly based on statistical census data. However, as these data are collected at various administrative levels (commune or district), they are frequently too coarse for a detailed analysis, and additional information is needed to refine the datasets. The Population Impact Assessment Service uses freely 
available EO-based land cover and land use data (Strategic Service) as well as locallyprovided data from the cities (Local Service) to refine this census information to specify the spatial distribution of the population. Knowing, for example, the nature of the urban fabric (residential or non-residential), or the number of commuters and work places can permit very detailed population estimates at night and during the day. Such spatially aggregated population data can then be used to assess the exposure of people to different climate and environmental threats.

The Local Service analyses the impact of climate change scenarios for the day-time population, the number of people in an area during normal business hours, in high resolution (building block level). The calculation is based on a variety of locally-provided input data concerning commuting, work place, or place of study. The results are ready-touse, easy-to-understand visualisations of the daytime population distribution which are web accessible and delivered in GIS ready formats. For the Strategic Service, the results are then further combined with information on environmental threats and climate change risks such as flood risk datasets, or outcomes of urban climate models, to derive the exposure of the population. For example, Figure 9 depicts population difference at day time and night time near Helsinki Central station and projected future sea flood impact on population (based on Table 2). Table 2 presents potential number of buildings and poeple (population per building) effected by three different river sea flood scenarios (20, 100 and 250 year flood event) during day- and night-time of a 250 year sea flood event. Figure 10 shows 3D visualisation of population impact assessment mainly to make this information more intuitive for citizens or other stakeholders.

Added Value: The service provides planners with new insights into the location of the population during both night and day, the real scale of commuting and the greatest agglomerations of people. Accordingly, city planners can derive new information on the number of population exposed to climatic impacts such as poor air quality, floods, storm waters, heatwaves and rising sea levels. The information can then be used to support more effective and targeted climate change adaptation and mitigation measures.

Stakeholder Engagement: The Population Impact Assessment Service has been developed in response to the user requirements from the cities of Helsinki and Milan. The partner cities required information about the day-time population distribution as such information were not available to them. The cities had only information on the population distribution based on statistical census data. However, as these data are normally collected at various administrative levels (commune or district), and are therefore too coarse for a detailed analysis. Thus, additional information on the distribution of the population during the daytime was needed to first refine the datasets and second to identify potential exposure of the population to various climatic and environmental impacts such as floods, heatwaves and air pollutants etc. during the day.

Stakeholder collaboration was furthermore essential in the development of the Local Service development to secure local input data (number of commuters, work places, students, etc.) in order to derive the daytime population distribution. Accordingly, the cities provided all the necessary input data and supported service development with constructive feedbacks, thereby allowing a continuous improvement of the service outcome. 
Product Development: This service has great potential for community awareness raising and development of other innovative products including traffic or public transport planning, and the creation of emergency/evacuation plans. Additionally, depending on data availability, demographic data can be used to further refine the datasets allowing for disaggregation by age group and gender, permitting focus on the elderly or young, for example. Furthermore, mobile phone derived data (using GPS or Cell Data Records) could also permit the generation of time-specific population distributions, for example every two or three hours. This information would offer a major opportunity for urban planning as it would capture the socio-economic dynamic of the city, vital intelligence for effective urban planning which is currently poorly understood.

Stakeholder Evaluation: Two expert users participated in the evaluation of the service, and considered it useful for planners, with intuitive interface, and providing substantial novel data. Specifically, the service was found to assist in the analyse of the effect of floods and heat waves on daytime populations, whilst it was recognised that the service is significantly more when combined with other datasets, such as heat wave maps.

\section{Discussion}

The central issue identified in this paper concerns the potentials for the tools and methodologies developed by the DECUMANUS project, in the context of top-down expert governance, to also support more participatory forms of governance and greater stakeholder engagement. Beyond assessment of the specifics of the tools and methodologies in question, as presented in this paper, other important considerations concerning the nature of change in urban governance and the drivers of this change, must also be considered. Taking this latter aspect as the first consideration it is necessary to view urban governance in relation to the transformation tendencies arising in response to urban complexity and the evolving dynamic of social and technological innovation (EXPGOV project, 2009).DECUMANUS tools and the question of their impact and effectiveness as well as their future potentials in responding to the central question of this paper should be understood in this context of urban governance and the extent to which they meet the needs of a newly transformed governance, and support both requirements for a more integrated as well as more participatory open governance. However, assessment of the potential for top-down derived tools to also serve bottom-up co-production, and the steps to achieve this, can only be considered in the context of their specific application. Here questions concerning their current effectiveness are important preliminary considerations for assessment of future potentials in the context of bottom-up engagement. The first aspect of this assessment focuses on the ecosystem of stakeholders surrounding the production of the DECUMANUS tools.

Here it is clear that the DECUMANUS tools and methodologies are not developed in isolation from the demands of a new governance model outlined in section 1. DECUMANUS tools have been developed in the "living laboratory" of collaborative pan-European research in which a rich milieu of expertise representing the full ecosystem of experience and skills has been deployed. Specifically, cities and their requirements for enhanced assessment and 
communication technologies applied in relation to urban planning decision-making processes have formed the bedrock and foundation of tool development.

Agile engagements from service providers in meeting these requirements have been moderated by research partners seeking a common language to define and drive the process of tool design and development. It is clear in this process that co-production of tools is principally derived from an expert perspective, but arguably this is fully appropriate to the essentially top-down nature of the city requirements. These tools and methodologies serve the requirements of city planners to secure a more integrated assessment of the interplay of socio-economic and environmental challenges in the territorial context of the city and city region. These are the tools that the experts require to apply their decision-making knowledge in the most effective way, and wider stakeholder engagement in their development is not essential. For example the top-down DECUMANUS service products provide necessary stimulus and new information for decision making that may not be achievable purely through bottom-up participatory methods. For instance, climate atlas project climate change effects for 2100 which may not be derived using bottom-up approaches. Nevertheless, the output of climate atlas enables new bottom-up initiatives to promote co-creation and co-design such as promotion of green strategies like electric cars to reduce Green House Gas emissions, etc.

The issue of the current effectiveness and future potentials of the DECUMANUS tools was also addressed in a series of dialogue workshops promoted by DECUMANUS in collaboration with external stakeholder advisory group including city networks. These networks included CEMR= (Council for European Municipalities and Regions) and EUROCITIES, hosting diverse stakeholders in discussion on the potentials for smart city governance enabled by DECUMANUS innovations. The dynamic of the workshop dialogues was focused on planning scenarios which typified challenges facing urban planning as a basis for the specification of ICT enabled solutions, the delivery of new forms of intelligence to the decision-making process, as well as more effective communication tools engaging stakeholders in the political decision making process.

One such scenario, the green infrastructure planning scenario provides a powerful narrative of integrated and participatory governance in which the different DECUMANUS tools can be assessed in respect of both top-down and bottom-up engagement in the planning process, and which assists in defining future development potentials. The development and implementation of planning strategies supporting green infrastructure require simultaneous planning engagement at different levels of governance. At the neighbourhood level in the planning of green space, green roof and tree cover, actual and potential, considerations of proximity and socio-demographic characteristics are paramount.

Neighbourhood green infrastructure proximity indicators must however also be connected with city-wide connectivity indicators, as neighbourhood solutions perform a vital role in ensuring the integrity of the green infrastructure network linking city centre to hinterland.

\footnotetext{
CEMR - http: / / www.ccre.org/

${ }^{3}$ Eurocities: http: / / www.eurocities.eu /
} 
DECUMANUS green roof and tree location indicators therefore drive integrated planning in combining with connectivity and accessibility indicators at city-wide level.

However, DECUMANUS tools also address the scope of participatory urban governance that extends beyond the requirements of integrated governance. In particular, whilst the DECUMANUS Earth Observation derived images capture key dimensions of the urban environment, including thermal and light emissions, climate change impacts, and green infrastructure frameworks, and provide a basis for integrated land use planning assessment methodologies, they also provide powerful images of the socio-economic and environmental reality of cities that offer a major opportunity for the development of new communication tools in urban environment.

DECUMANUS images depict the flows of light pollution and heat loss from our cities, as well as the future impacts of climate change for human well-being, and so support the development of communication tools that can engage citizens and mobilise the societal behavioural changes necessary to secure the sustainable city of tomorrow. In this respect the Climate Atlas images of the health impacts of climate change in respect of increased mortality according to business as usual scenarios at city scale, bring home most directly to citizens the need for change. "Greening the City" campaigns, for example, are deployed by the majority of cities to drive behavioural change to support the implementation of green infrastructure and nature based planning solutions that provide major "win-win" policy cobenefits (European Commission, 2013c). These solutions not only enhance access to green open space, they also provide relief from climate change impacts, restore biodiversity, enhance ecosystem services, and deliver quality of life and social cohesion in cities.

Beyond campaigns, the co-production potentials of DECUMANUS solutions are also evident in the framework of citizen science where specific community derived inputs offer great potential for further and necessary product development and validation. Classically stakeholder engagement is most evident the closer the issue in space and time, according to the dictum of 'not in my backyard'. Accordingly, community engagement in green infrastructure planning at the neighbourhood level is anticipated and highly effective as neighbours are the experts in their local community. Equally co-production validation potential exists in the citizen verification of green canopy/tree locations, as well as green roof actual distribution and potentials.

The potential of the DECUMANUS tools therefore, to drive a fully integrated as well as participatory open governance with full engagement of all stakeholders including citizens according to a model of open governance is considered substantial. Beyond the community neighbourhood level and back yard interventions however, the issue of incentivisation to realise the full potentials of this bottom-up engagement in the co-production of the tools remains a challenge that needs urgent consideration and resolution.

\section{Conclusions}

Based on presentation of the DECUMANUS service and the above discussion the following conclusion are derived: 
i) DECUMANUS service products mainly use top-down engagement of urban planning experts to develop and deliver a unique set of visually rich intelligence services which are economically viable and expensive to achieve using non-EO based methodologies. This is mainly because of the capability of satellite-based earth observation data to capture various environmental, land cover and land use aspects which otherwise is expensive to generate or not feasible.

ii) The service development process was user driven and co-produced by engaging with city planning stakeholders, domain experts appropriate to the primary use of the tools in an integrated urban management decision making process. DECUMANUS service products were tailored to specific needs of the city experts.

iii) DECUMANUS service products provide vital intelligence for city planners in regard to territorial impact assessment and decision making. At the same time these service products can be considered smart city drivers for co-creation and co-production by enabling city administrations to engage with wider stakeholders including civil society organisations, business representatives and citizens. In this respect these service products provide visually powerful communication tools to engage with wider stakeholders in raising awareness and mobilizing response to societal challenges and political priorities including climate change, and resource efficient cities. EO data generated by these DECUMANUS services provide evidence-based information that can help citizens in informed decision-making. It also provides the opportunity for local stakeholders to develop new bottom-up tools to co-create new applications supporting new public services for citizens or businesses.

iv) DECUMAUS products offer significant added value to territorial decision making at both strategic and local levels of governance. Further development of selected services could be achieved by developing new bottom-up tools with the objective of co-producing in engaging with citizens and in the frame of citizen science and collecting additional data. For instance the thermal energy efficiency product development process could be greatly improved by citizen participation during airborne LiDAR scanning, in validating local temperature. Similarly, the services can be further enriched via crowd-sourcing campaigns e.g. for the tree mapping service in identifying tree species. Furthermore, outputs of selected services including green roofs, thermal energy, light emission, day-night population can be validated by citizens by identifying errors to improve the service development process.

All the above clearly indicates that DECUMANUS services top-down governance oriented information tools also have great potential for developing bottom-up tools for co-creation and co-design of new decision making and policy implementation support in the context of open governance.

\section{Acknowledgements}

The DECUMANUS project is partly funded through European Commission Framework Programme Seven. The UPM authors also acknowledge the computer resources and technical assistance provided by the Centro de Supercomputación y Visualización de Madrid (CeSViMa). The UPM authors thankfully acknowledge the computer resources, technical expertise and assistance provided by the Red Española de Supercomputación). We also 
acknowledge the support and cooperation from DECUMANUS project partners for the development of DECUMANUS service products.

\section{References}

Bunt, L and Harris, M. 2010. Mass Localism: A way to help small communities solve big social challenges. NESTA Discussion paper [online].

Chua, B., and Dyson, L. 2004. Applying the ISO 9126 model to the evaluation of an e-learning system. In Proc. of ASCILITE. pp. 5-8.

Copernicus. 2016. - EU Earth Observation Programme. http:/ / www.copernicus.eu/

Davies, S., Selin, C., Gano, G., and Pereira, G. 2012. Citizen engagement and urban change: Three case studies of material deliberation. Cities Elsevier Journal, 29, pp.351-357.

DECUMANUS Project. 2013. http:/ / www.decumanus-fp7.eu

DECUMANUS Project. 2014. User Requirements Definition (I), Deliverable 2.1, Feb / March 2014.

Eckhardt, F., and Elander, I, (Eds) 2011. Urban Governance in Europe. ISBN: 978-3-8305-1502-9, BWV -VERLAG.

European Commission. 2013a. A vision for public services, DG-CNCT. Published 13/06/2013.

European Commission. 2013b. Powering European Public Sector Innovation: Towrds A New Architecture. Expert repot. EUR 13825 EN.

European Commission. 2013c. Thematic issue: Ecosystem-based Adaptation. Issue 37.

EXPGOV project. 2009. Exploring emerging ICT-enabled governance models in European Cities.

Deliverable D.1 - Final version.

Hanzl, M. 2007. Information technology as a tool for public participation in urban planning: a review of experiments and potentials. Design Studies, Volume 28, Issue 3, May 2007, pp.289-307.

Innes, J., and Booher, D. 2004. Reframing Public Participation: Strategies for the 21st Century. Planning Theory and Practice 5(4), pp. 419-436.

Insight project. 2013. Policy Modelling and Governance Tools for Sustainable Urban DevelopmentState of the art and Future Challenges. [online]

Jacquier C. 2008. Urban governance: forging a path between complications and complexity. Paper presented for the Reims symposium "Towards New Territorial Governance" .

Kahila, M., \& Kyttä, M, 2010. SoftGIS as a Bridge-builder in Collaborative Urban Planning. In: Journal of Planning Support Systems- Best Practice and New Methods, pp.389-411.

Khan, Z., Ludlow, D., and Caceres, S. 2013. Evaluating a collaborative IT based research and development project. Evaluation and Program Planning, 40, pp. 27-41.

Khan, Z., Ludlow, D., and Loibl, W. 2013. Applying the CoReS requirements development method for building IT tools for urban management systems: The UrbanAPI project. Theoretical and Empirical Researches in Urban Management, 8 (4). pp. 25-59. 
Khan, Z., Ludlow, D., Loibl, W. and Soomro, K. 2014. ICT enabled participatory urban planning and policy development: The UrbanAPI project. Transforming Government: People, Process and Policy, 8 (2). pp. 205-229.

Kingston, R. 2007. Public Participation in Local Policy Decision-making: The Role of Web-based Mapping. The Cartographic Journal, ICA Special Issue 2007, 44(2), pp. 138-144.

Kyttä, M. 2011. The inhabitant friendly, health promoting urban structure. Conference Proceedings, Open Space: People Space 3. Edinburgh. pp. 11-18.

Lang, V., and Sittler, P. 2012. Augmented Reality for Real Estate. Proceedings, 18th Annual Pacific-Rim Real Estate Society Conference, Adelaide.

Lew, P., Olsina, L. and Zhang, L. 2010. Web Engineering: 10th International Conference, ICWE 2010, Vienna Austria. July 5-9, 2010. Proceedings. In B. Benatallah et al., eds. Berlin, Heidelberg: Springer Berlin Heidelberg, pp. 218-232.

Misuraca, G et al. 2010. Envisioning Digital Europe 2030: Scenarios for ICT in Future Govenance and Policy Modelling. Misuraca G and Lusoli W (Eds), JRC report. EUR 24614 EN - 2010.

Poplin, A. 2011. Playful public participation in urban planning: A case study for online serious games. Computers, Environment and Urban Systems, Volume 36, Issue 3, pp. 195-206.

Rowe, G., and Fewer, L. 2000. Public Participation Methods: A Framework for Evaluation. Science, Technology, and Human Values, Vol. 25, No. 1 (Winter, 2000), pp. 3-29.

Rowe, G. and Fewer, L. 2005. A Typology of Public Engagement Mechanisms. Science, Technology, and Human Values, Vol. 30, No. 2 (Spring, 2005), pp. 251-290.

Silva, C. 2010. Handbook of Research on E-Planning: ICTs for Urban Development and Monitoring. IGI Global Snippet, 2010.

Taylor, N. 2007. Urban Planning Theory since 1945. London, Sage.

United Nations. 2010. Shanghai Manual - A Guide for Sustainable Urban Development of the $21^{*}$ Century. World Expo 2010 Shanghai, China,

http://www.un.org/esa/dsd/susdevtopics/sdt_humasett_capacitybuilding.shtml

Wampler, B., and McNulty, S. 2011. Does Participatory Governance Matter? Exploring the Nature and Impact of Participatory Reforms, Comparative Urban Studies Project.

http:/ / www.wilsoncenter.org/publication/does-participatory-governance-matter

Wong, C. 2011. Decision-making and problem-solving. in Hull, A. Alexander E.R., Khakee, A. and Woltjer, J., Evaluation for Participation and Sustainability in Planning, Routledge, UK. Yigitcanlar, T., Velibeyoglu, K., and Baum, S. 2008. Creative Urban Regions: Harnessing Urban Technologies to Support Knowledge City Initiatives. IGI Global Snippet. 


\section{Figures}

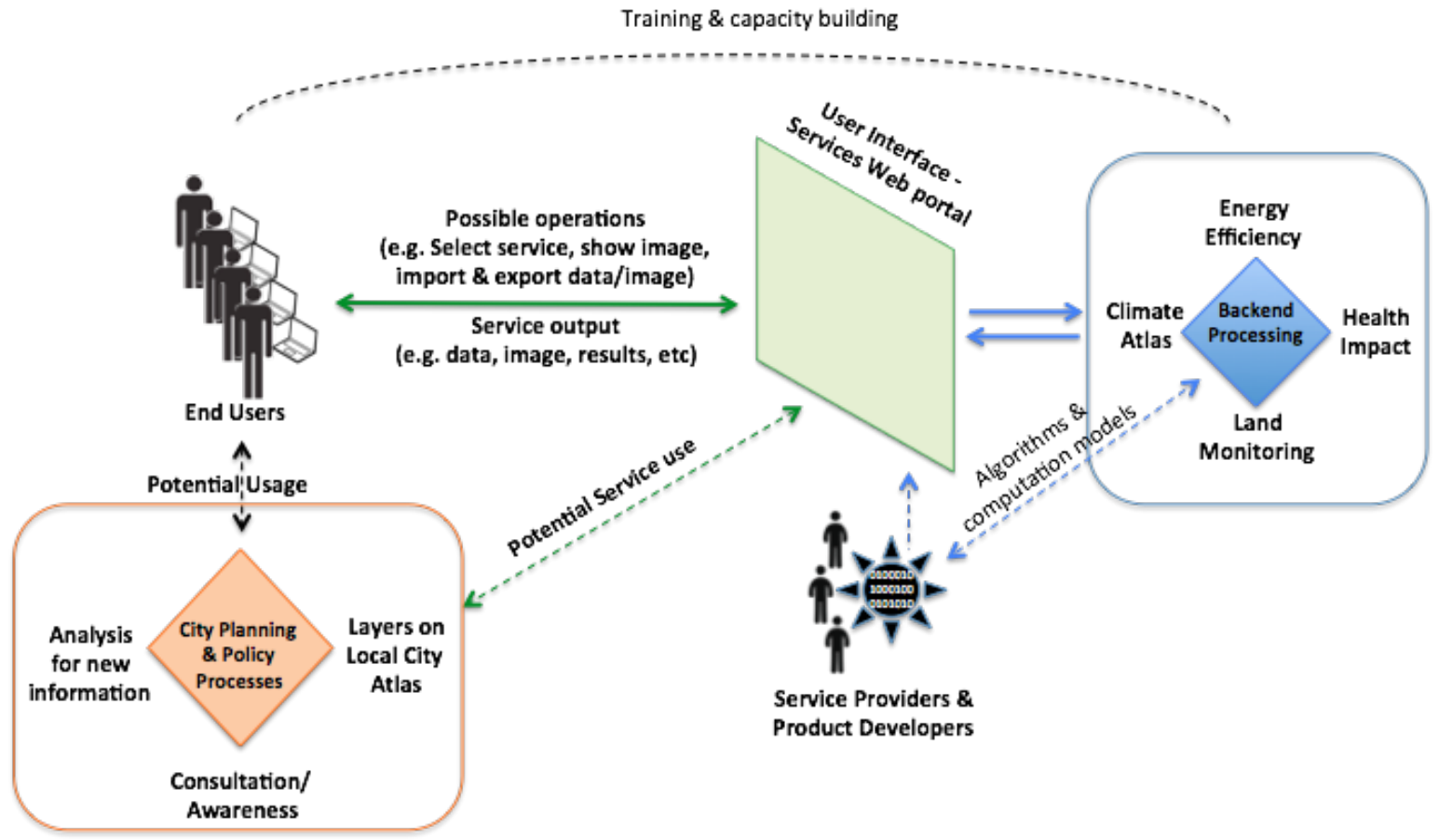

Figure 1: Interaction of end users (city stakeholders e.g. urban planners, decision makers, GIS experts etc) with DECUMANUS services via web portal

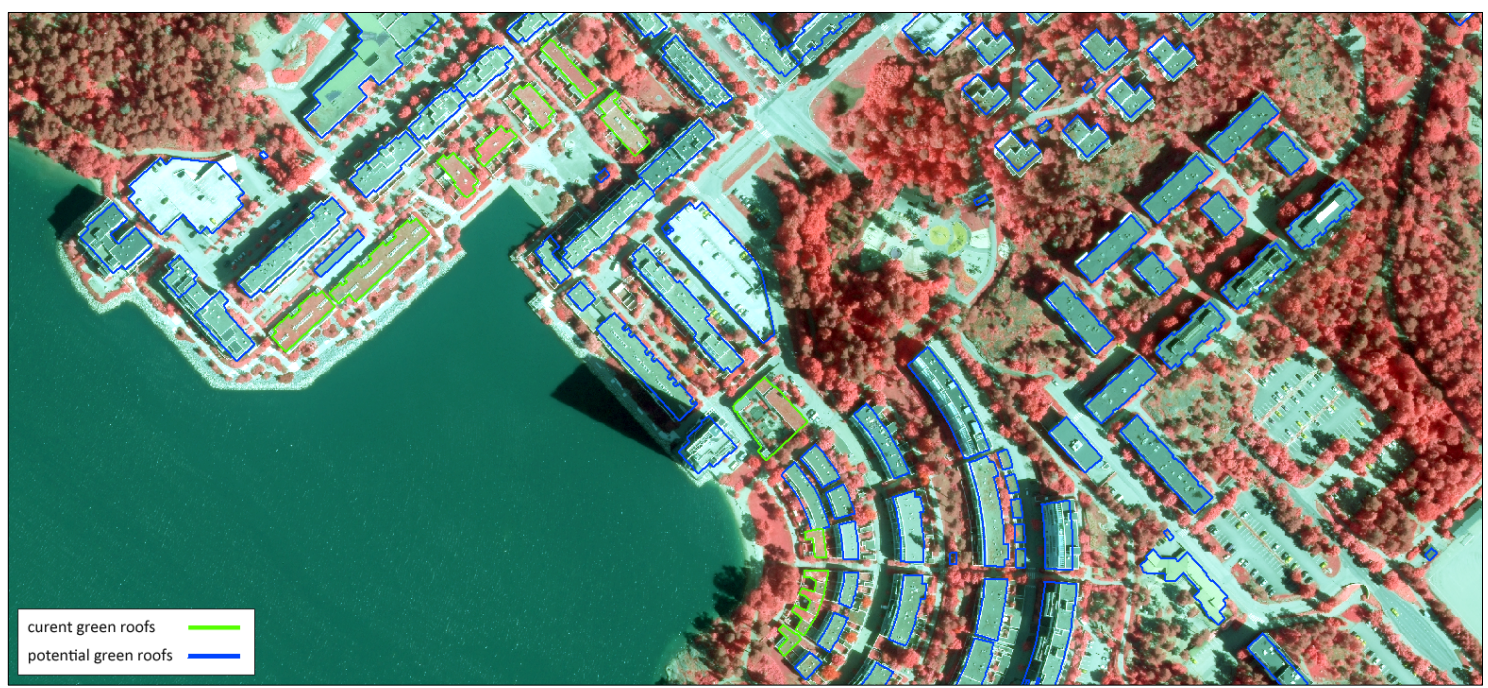




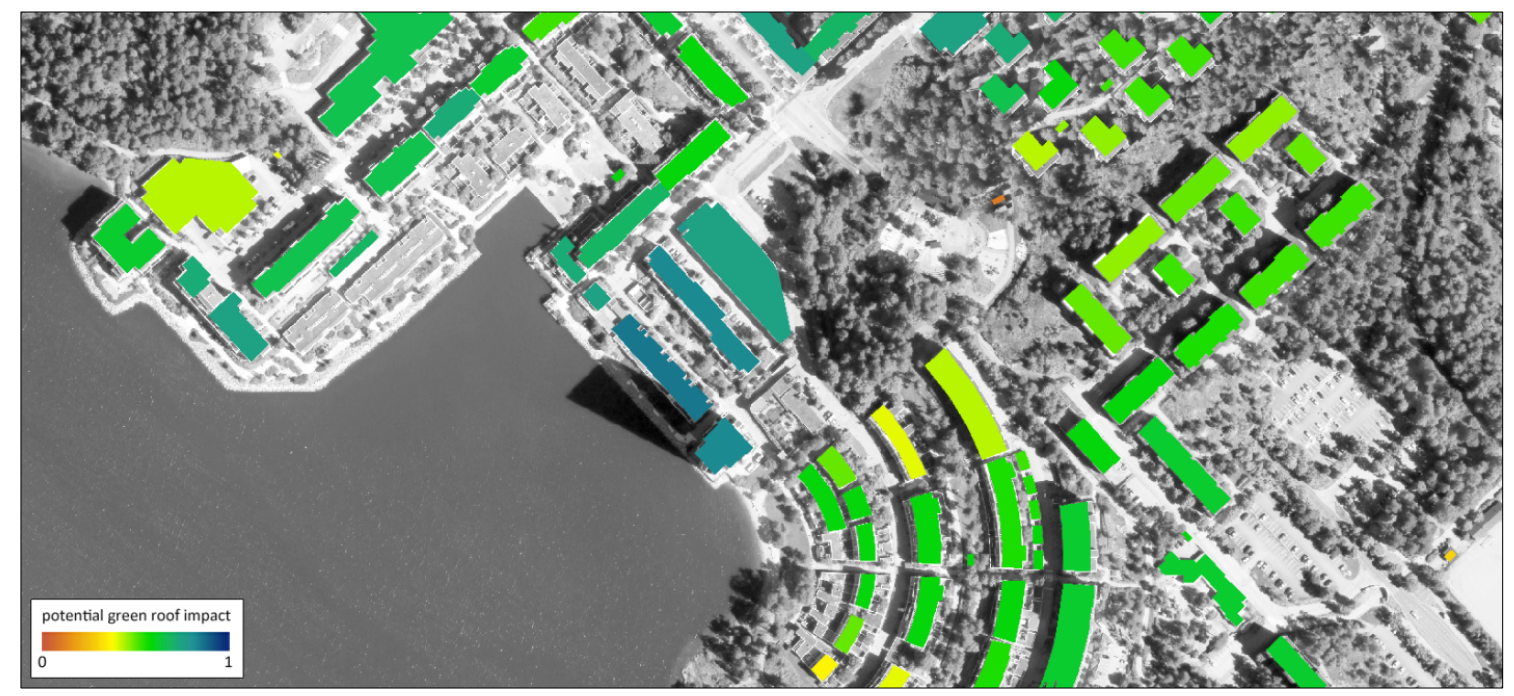

Figure 2: Current and potential green roof maps - Helsinki (above); corresponding potential green roof impact map (below)
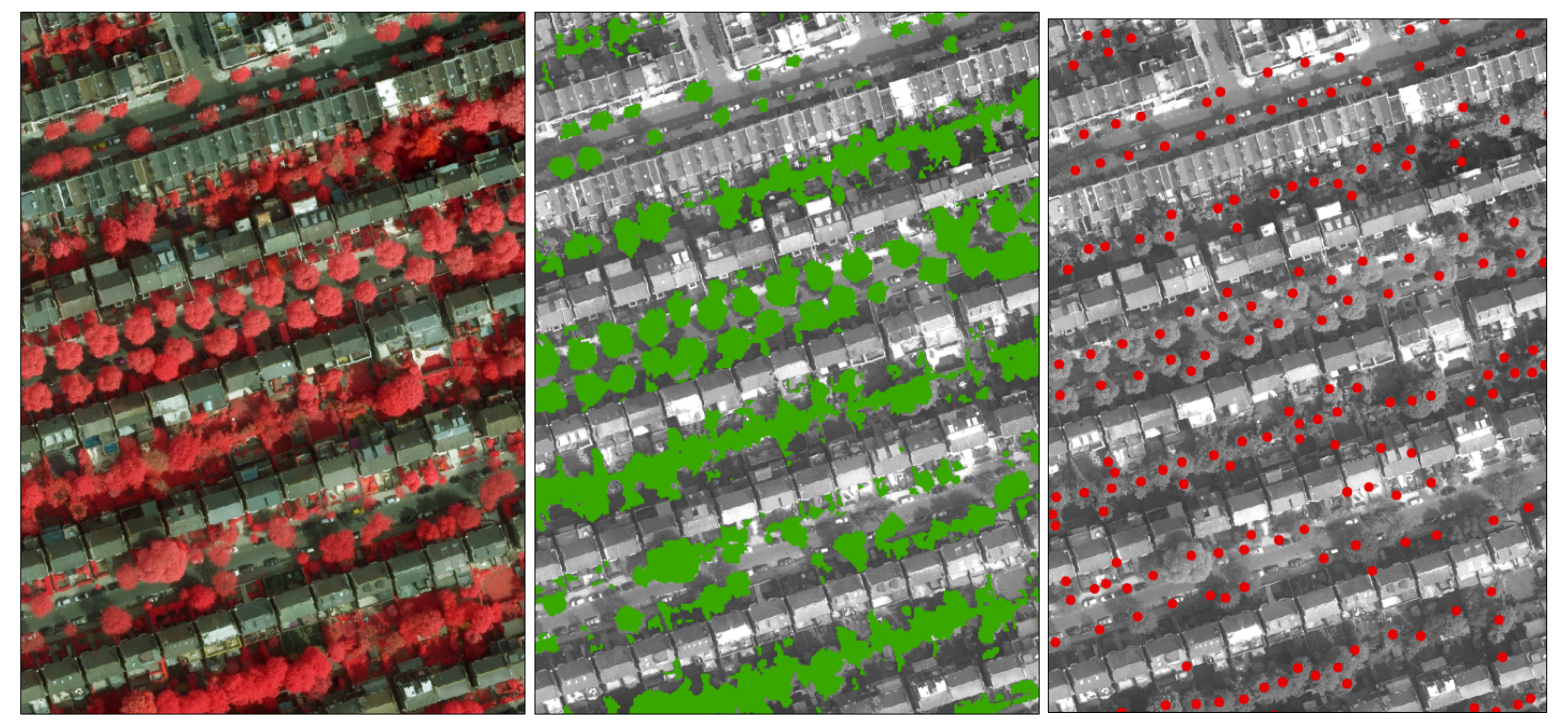

Figure 3: CIR airborne imagery (left) and (middle) corresponding estimated tree canopy coverage [in green] (b), and tree locations [in red] (c) in the Royal Borough of Kensington and Chelsea, London 

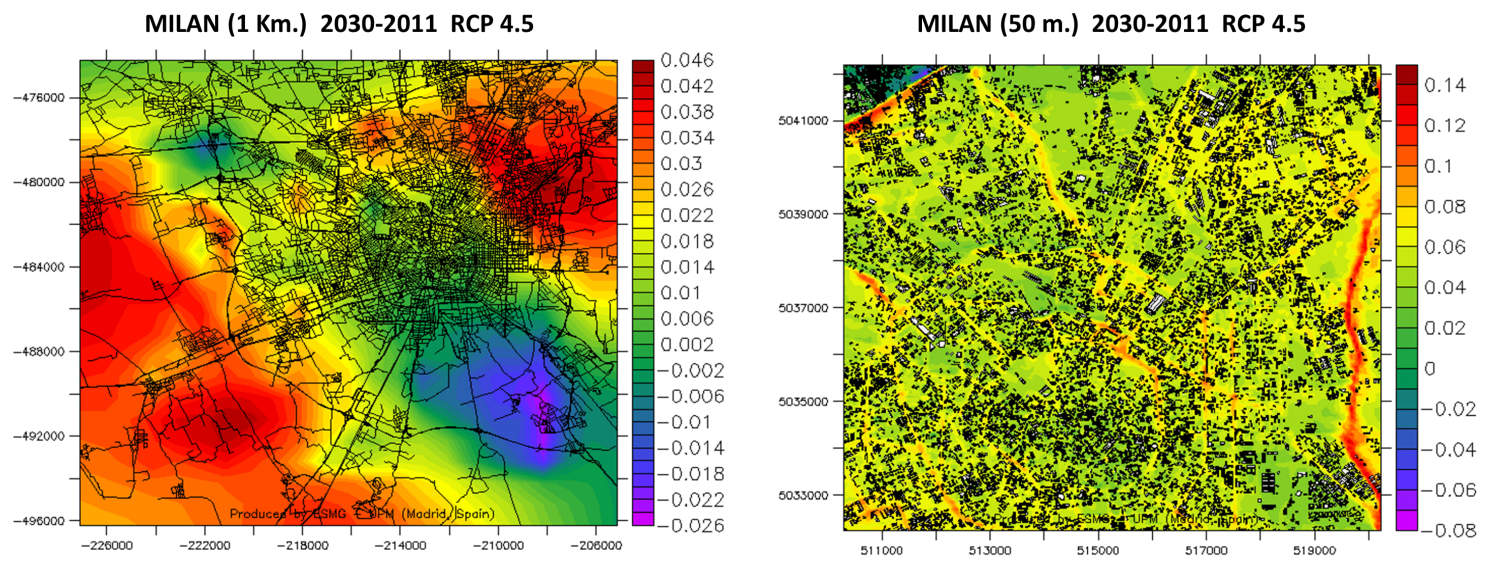

Differences (\%) of annual mean on daily mortality by respiratory causes due to daily average PM10 concentrations

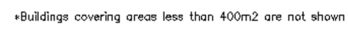

Figure 4: Differences (\%) of annual mean in daily mortality by respiratory causes due to PM10 exposure in Milan with $1 \mathrm{Km}$ spatial resolution (left) and 50m (right) for 2030 with climate scenario RCP 4.5
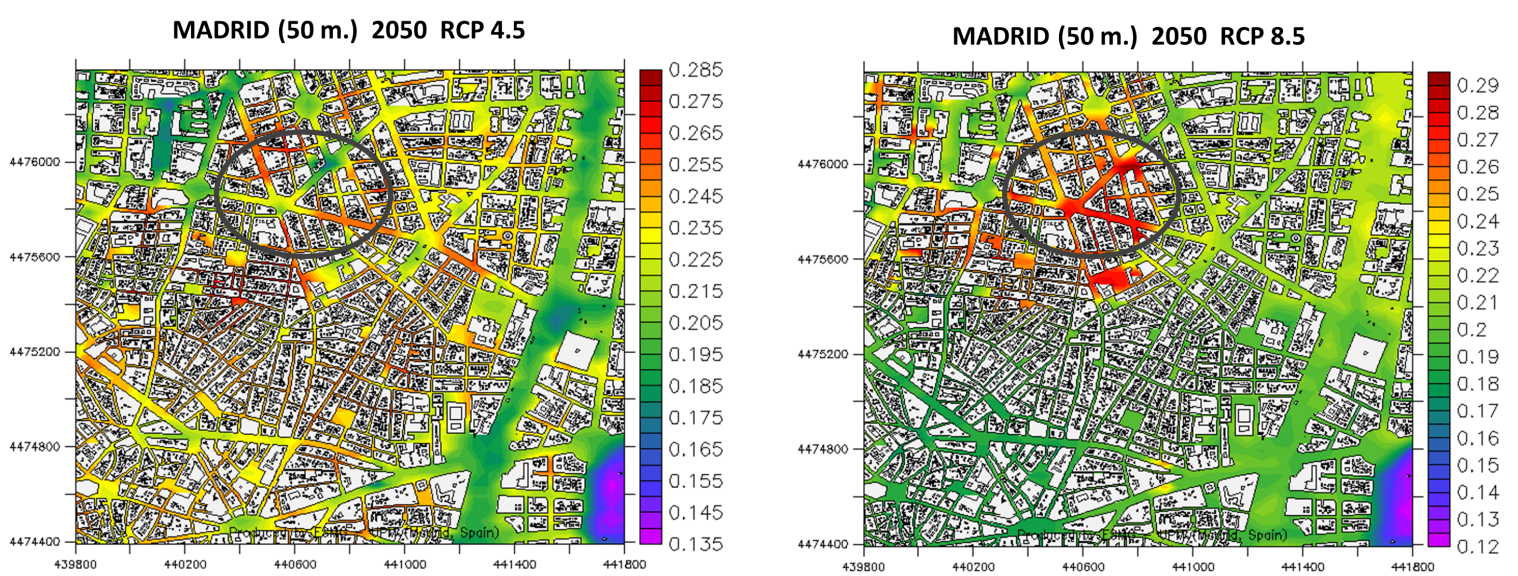

OVERALL AGGREGATE EXPOSURE INTENSITY INDICATOR : Identifies the more sensible areas for global climate change based on 15 climate indicators

Figure 5: Overall aggregate exposure intensity indicator for Madrid area with 50m spatial resolution for year 2050 with climate scenarios RCP 4.5(left) and RCP 8.5 (right) 


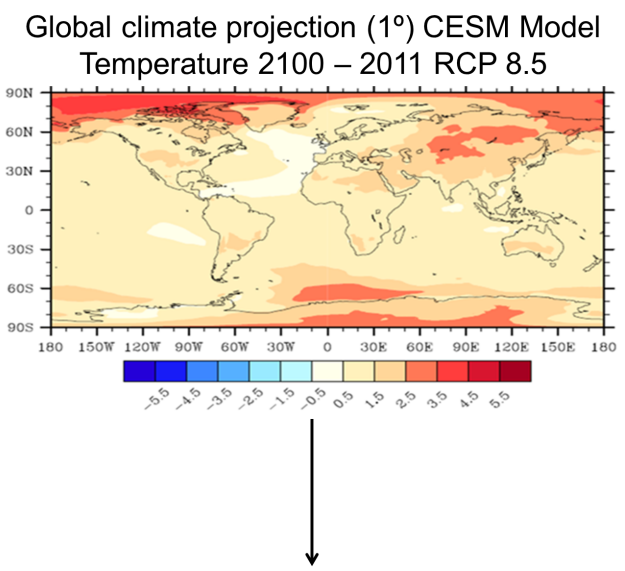

Europe $(25 \mathrm{Km})$

Temperature $2100-2011$ RCP 8.5

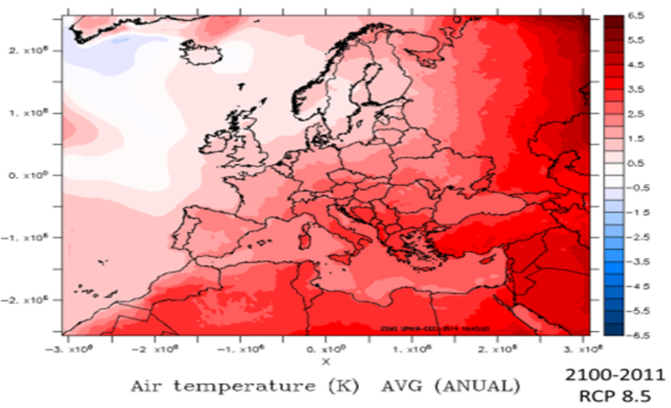

DECUMANUS DYNAMICAL DOWNSCALING APPROACH

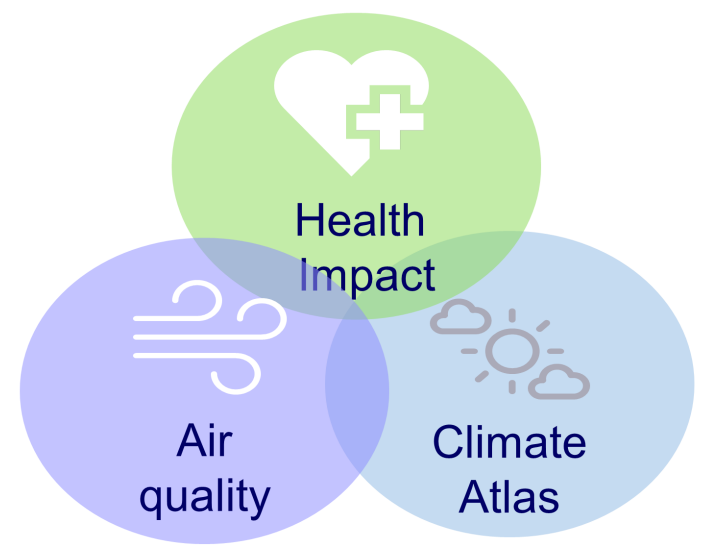

Kensington \& Chelsea (50 m.) $2100-2011$ RCP 8.5

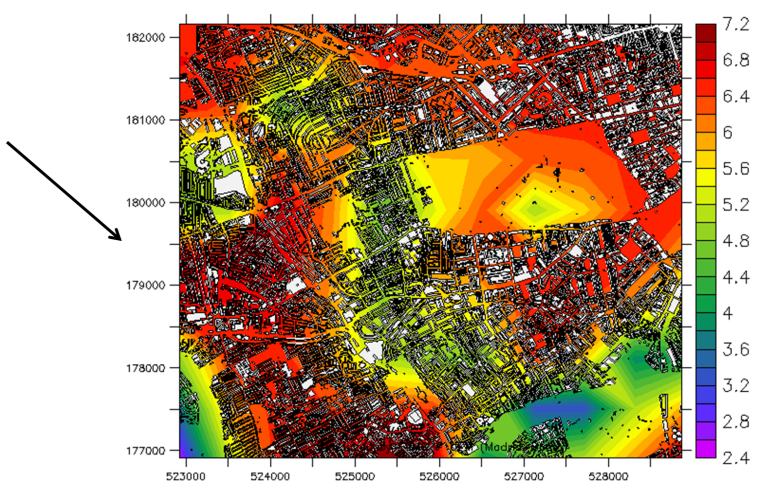

Differences (\%) of annual mean increment on daily mortality by respiratory causes due to apparent temperature

Figure 6: Integrated global climate impact assessment tool using a dynamical downscaling approach to go from global to local 


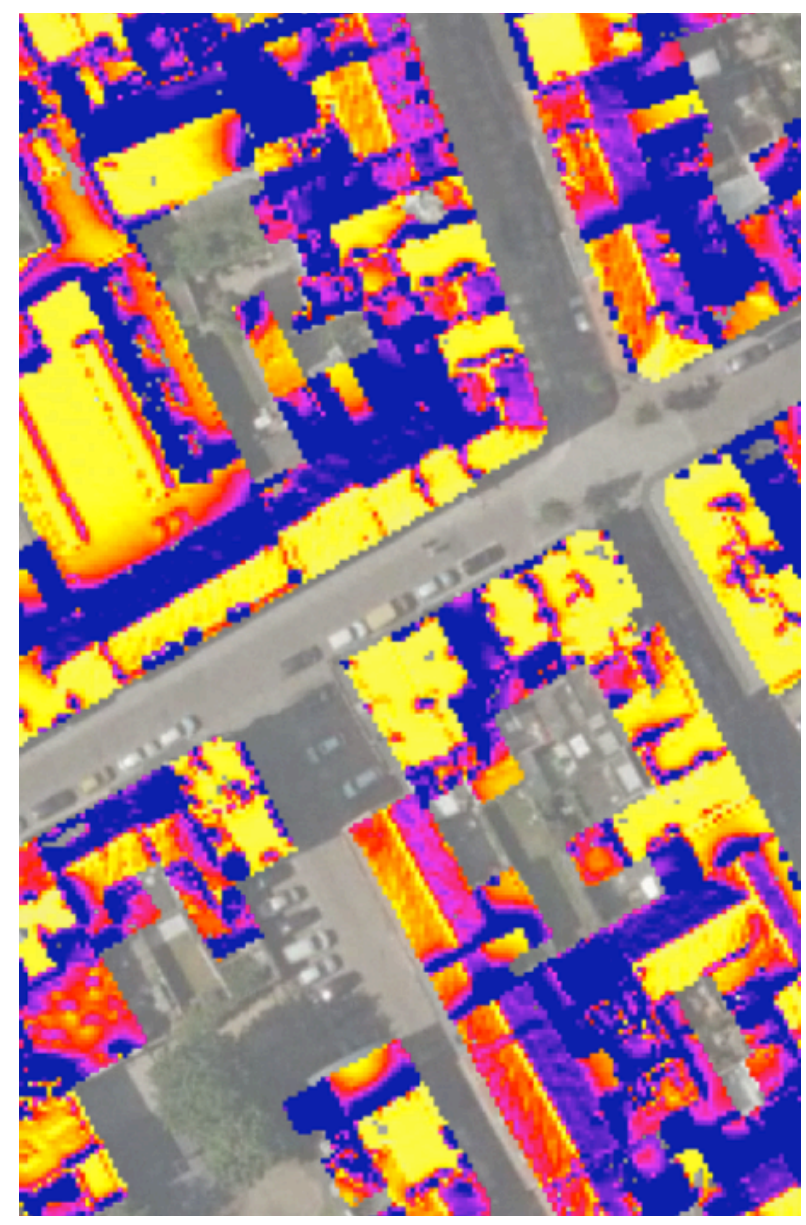

a) based on a model of solar insolation

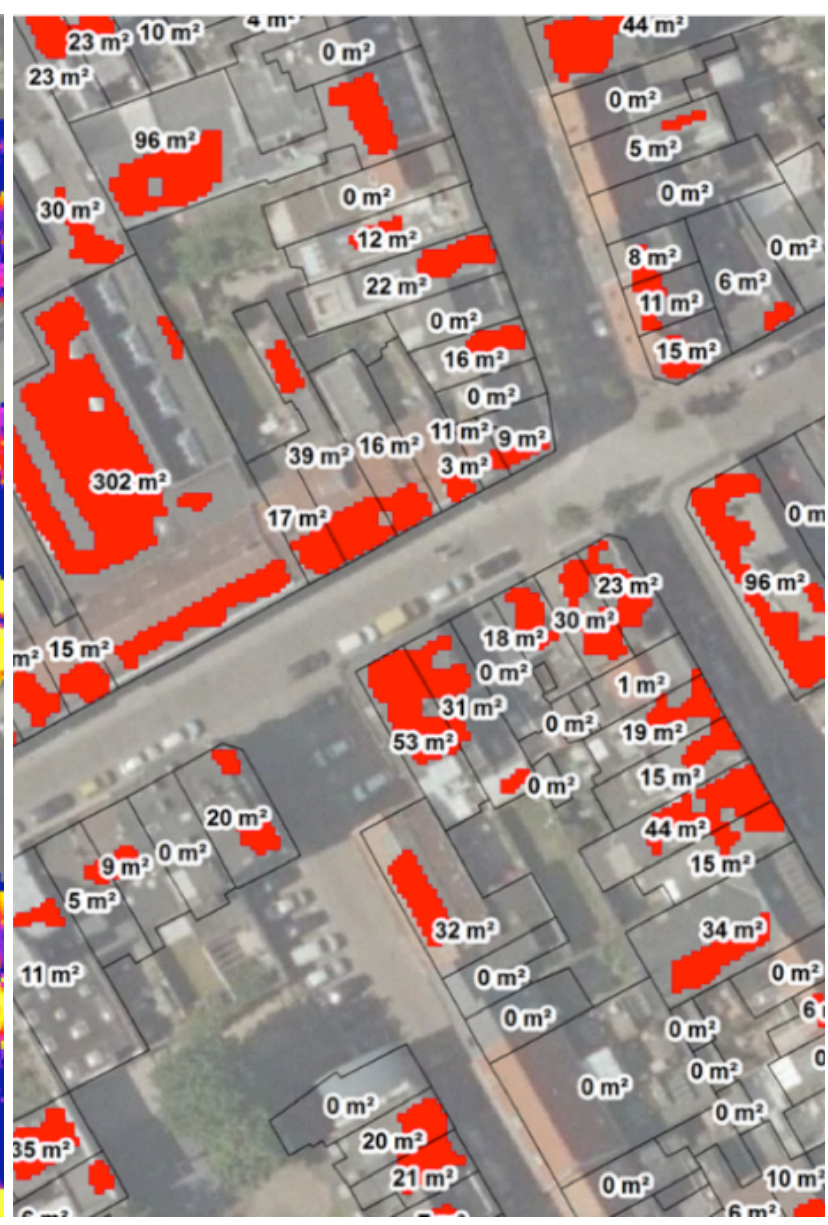

b) minimum insolation and geometric criteria for the installation of solar panels

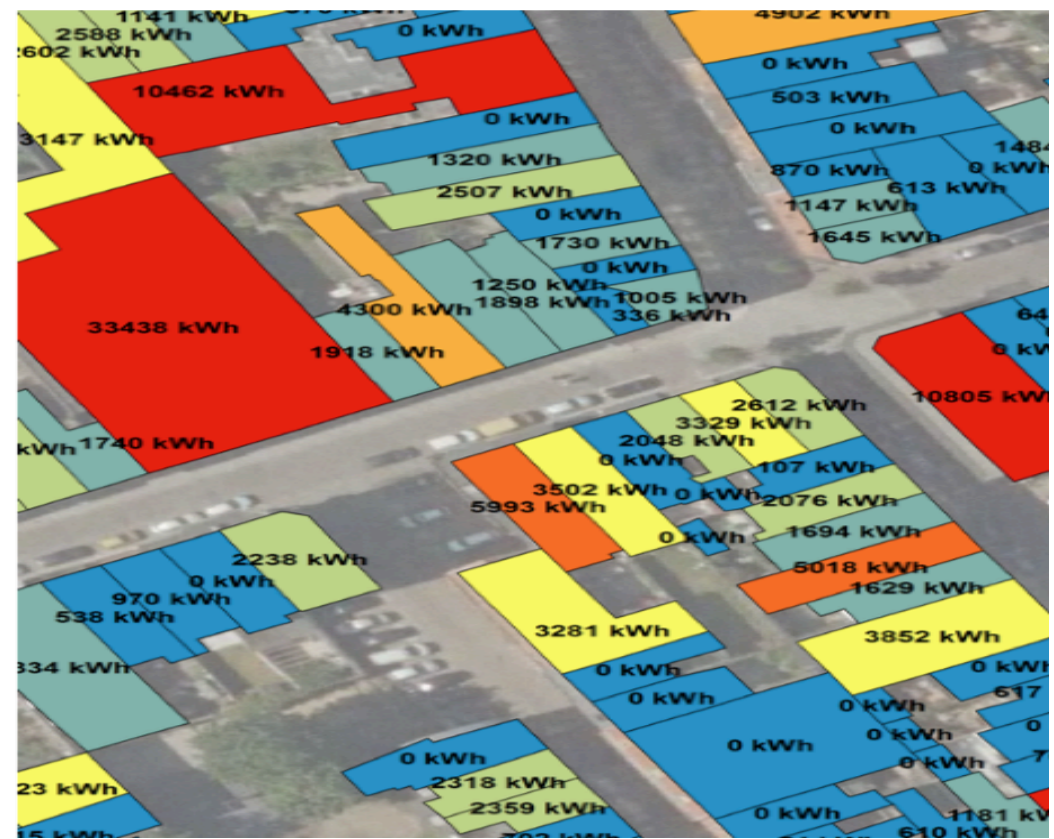

c) derived expected annual electricity yield

Figure 7: Determination of the roof photovoltaic potential in Antwerp 


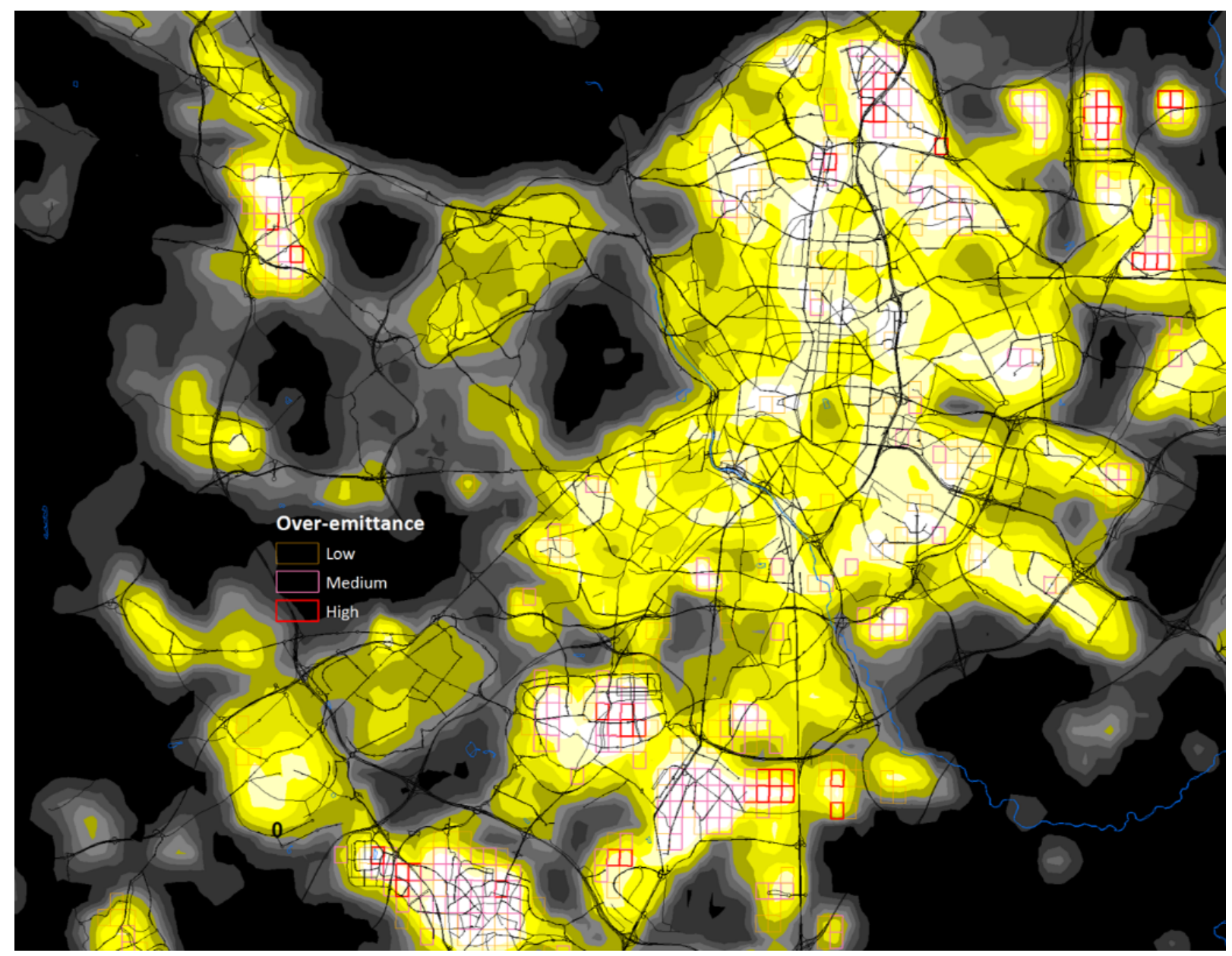

Figure 8: Madrid night-time light emissions based on a composite of images of May 2014, taken by the DNB sensor on board Suomi-NPP satellite 


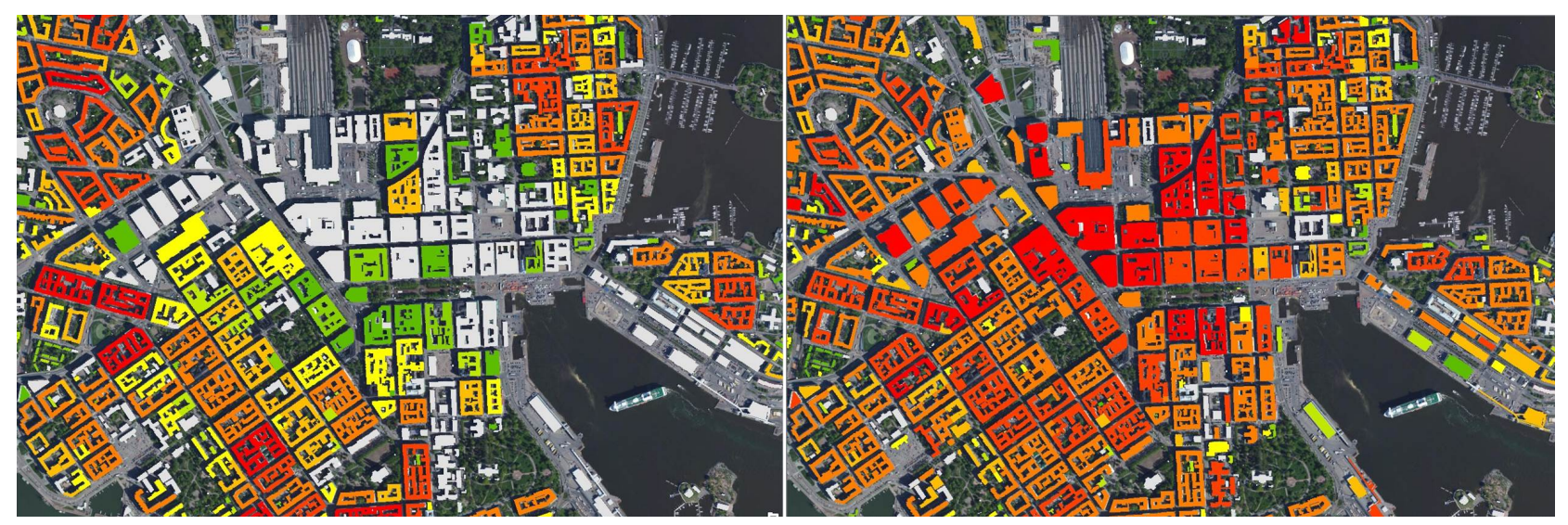

a)

b)

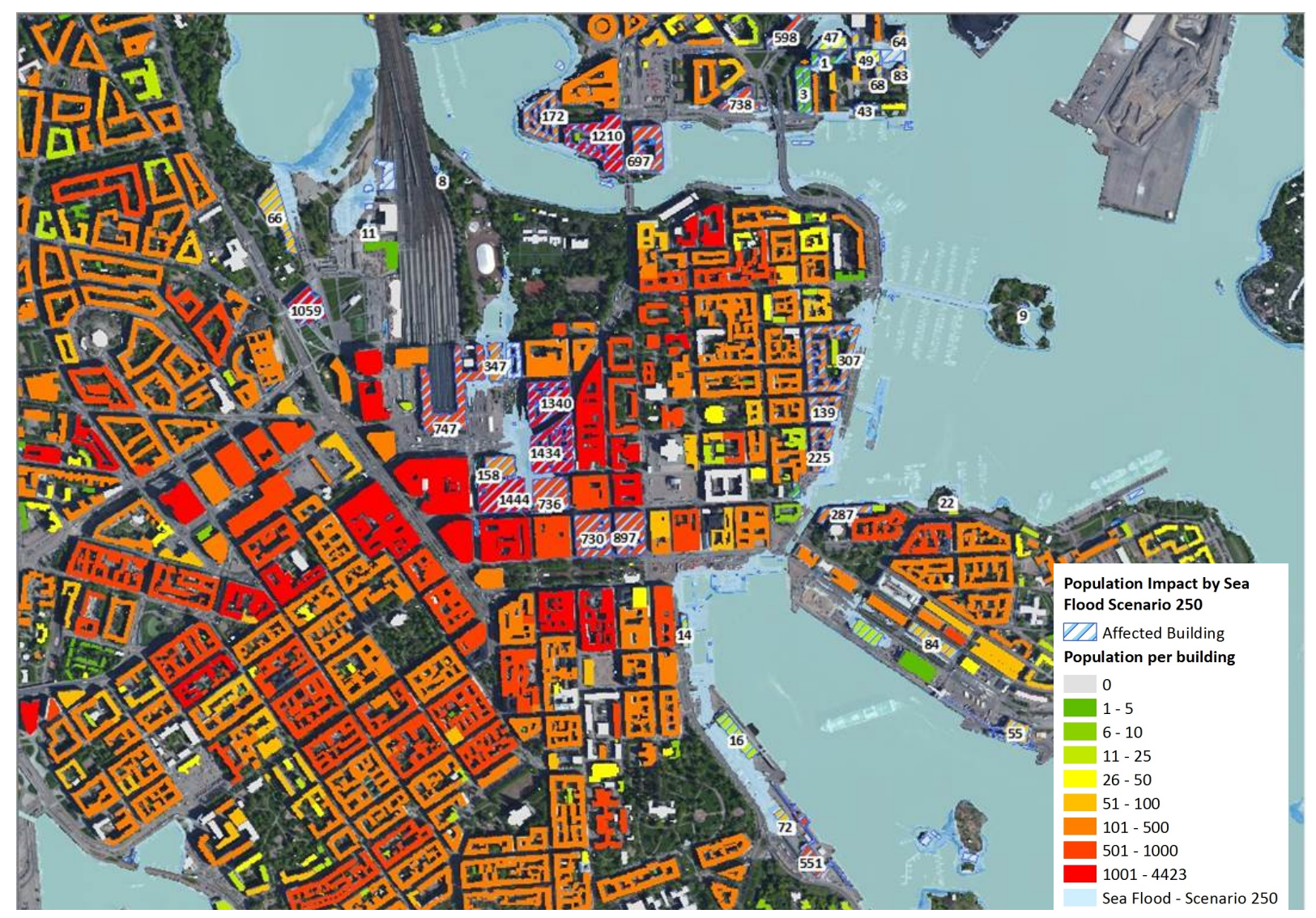

c)

Figure 9: Helsinki - Three different Local Service outcomes - a) From left first night and b) second daytime population near Helsinki central station. c) Third image shows potential impact of a 250 year sea flood event and the number of potentially affected population per building 


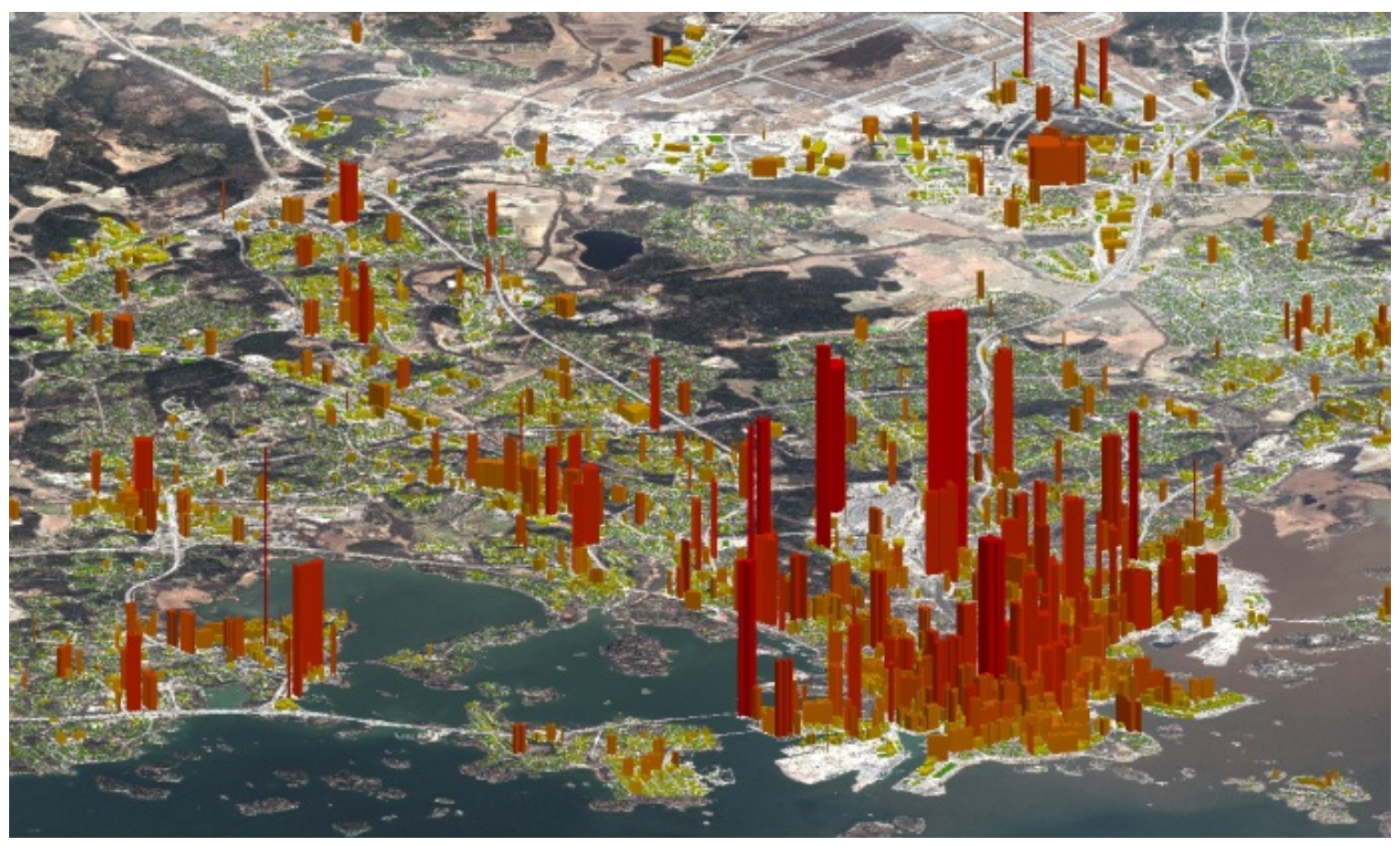

Figure 10: Helsinki - central area 3D visualisation of Local Service

\section{Tables}

Table 1: : DECUMANUS Services - Systematic Analysis

\begin{tabular}{|l|l|}
\hline Aspects & Specification \\
\hline Product Description & Description of tools and products developed during the project \\
\hline Added Value & $\begin{array}{l}\text { Assessment of the added value in terms of utility and state-of-the-art. For } \\
\text { example, benefits arising in respect of improved decision-making due to } \\
\text { environmental assessment methodologies or enhanced communication } \\
\text { between planning and community stakeholders as a result of improved } \\
\text { visualization of data/information. }\end{array}$ \\
\hline Stakeholder Engagement & $\begin{array}{l}\text { Nature of stakeholder engagement in product development. For example, with } \\
\text { reference to DECUMANUS engagement with city planners, and the } \\
\text { stakeholder group, in the specification and development of the product. }\end{array}$ \\
\hline Product Development & $\begin{array}{l}\text { Extent and nature of additional product improvement/development if the tools } \\
\text { created in the framework of co-production. In particular, key questions } \\
\text { concern the potential added value of enhanced bottom-up engagement } \\
\text { in product specification and development compared the more } \\
\text { conventional top-down approach adopted in DECUMANUS. }\end{array}$ \\
\hline Stakeholder Evaluation & $\begin{array}{l}\text { Stakeholder evaluation of service product. A Criteria Indicators and Metrics } \\
\text { (CIM) version } 2 \text { based approach is used to assess the usability, efficiency and } \\
\text { effectiveness of the service products. }\end{array}$ \\
\hline
\end{tabular}


Table 2: potentially affected number of buildings and person

\begin{tabular}{|c|c|c|c|c|c|c|c|c|c|c|}
\hline \multirow{4}{*}{ HELSINKI } & & \multicolumn{3}{|c|}{ Potentially affected buildings } & \multicolumn{3}{|c|}{ Potentially affected people (night) } & \multicolumn{3}{|c|}{ Potentially affected people (day) } \\
\hline & & $\begin{array}{c}20 \text { year } \\
\text { flood event }\end{array}$ & $\begin{array}{c}100 \text { year } \\
\text { flood event }\end{array}$ & $\begin{array}{c}250 \text { year } \\
\text { flood event }\end{array}$ & $\begin{array}{c}20 \text { year } \\
\text { flood event }\end{array}$ & $\begin{array}{c}100 \text { year } \\
\text { flood event }\end{array}$ & $\begin{array}{c}250 \text { year } \\
\text { flood event }\end{array}$ & $\begin{array}{c}20 \text { year } \\
\text { flood event }\end{array}$ & $\begin{array}{c}100 \text { year } \\
\text { flood event }\end{array}$ & $\begin{array}{c}250 \text { year } \\
\text { flood event }\end{array}$ \\
\hline & & 497 & 697 & 745 & 427 & 1.475 & 2.111 & 1.100 & 1.984 & 2.34 \\
\hline & Sea flood & 1.722 & 2.528 & 3.058 & 4.939 & 8.806 & 12.343 & 14.754 & 25.677 & 33.698 \\
\hline
\end{tabular}

